Quim. Nova, Vol. 35, No. 9, 1884-1886, 2012

\title{
POLARÍMETRO VIRTUAL: DESENVOLVIMENTO, UTILIZAÇÃO E AVALIAÇÃO DE UM SOFTWARE EDUCACIONAL
}

\author{
José Nunes da Silva Júnior* e Francisco Geraldo Barbosa \\ Departamento de Química Orgânica e Inorgânica, Centro de Ciências, Universidade Federal do Ceará, CP 6021, 60451-970 \\ Fortaleza - CE, Brasil \\ Antonio José Melo Leite Junior \\ Instituto UFC Virtual, Centro de Ciências, Universidade Federal do Ceará, 60451-970 Fortaleza - CE, Brasil
}

Recebido em 13/2/12; aceito em 26/4/12; publicado na web em 3/8/12

\begin{abstract}
VIRTUAL POLARIMETER: DEVELOPMENT, USE AND EVALUATION OF AN EDUCATIONAL SOFTWARE APPLICATION. Optical activity is the ability of chiral substances to rotate the plane of plane-polarized light and is measured using an instrument called a polarimeter. An educational software application to explore, both interactively and visually, the concepts related to polarimetry to facilitate their understanding was developed. The software was field-tested and a questionnaire evaluating the graphics interface, usability and the software as an educational tool, was answered by students. The results characterized the computer application developed as an auxiliary tool for assisting teachers in lectures and students in the learning process.
\end{abstract}

Keywords: polarimetry; optical activity; educational software.

\section{INTRODUÇÃO}

A utilização das tecnologias interativas no ensino vem sendo discutida há muitos anos. ${ }^{1}$ Nos dias atuais, a Tecnologia da Informação e Comunicação tem se caracterizado como um recurso inestimável para a busca e manipulação do conhecimento, de forma que o computador pode ser um excelente auxiliar no processo ensino-aprendizagem, através da publicação e consulta de informações distribuídas pela internet ou do uso de softwares educacionais. ${ }^{2}$ Acredita-se que a tecnologia da informação possa ser utilizada como uma estratégia de ensino que permite desenvolver com sucesso um tópico ou conteúdo em sala de aula. ${ }^{3}$ Desta forma, a produção de novos softwares educacionais em todas as áreas do conhecimento tem sido cada vez mais objeto de pesquisas, provocando uma verdadeira revolução na concepção de ensino e aprendizagem.

Na internet encontram-se disponíveis diversos sítios com tutoriais, animações, vídeos, simulações, hipertextos/hipermídias ${ }^{4}$ na área da Química. Grupos de pesquisa, no Brasil, têm desenvolvido vários softwares educacionais relacionados à bioquímica, ${ }^{5}$ tabelas periódicas, ${ }^{6}$ estudo dos gases ${ }^{7}$ termoquímica e química orgânica, ${ }^{8}$ estrutura atômica, ${ }^{2}$ equilíbrio químico, ${ }^{9}$ titulação, ${ }^{10}$ soluções químicas ${ }^{11}$ e estequiometria. ${ }^{12}$ Todos estes aplicativos têm em comum o objetivo de melhorar o processo de ensino-aprendizagem de temas específicos de difícil aprendizado pelos estudantes. Este cenário nos motivou a desenvolver um software educacional simples, interativo e gratuito, que auxiliasse professores e estudantes na abordagem dos conceitos e cálculos relacionados à polarimetria.

\section{DESCRIÇÃO DO SOFTWARE}

\section{Plataforma escolhida}

A plataforma Adobe Flash ${ }^{13}$ foi utilizada como base para o desenvolvimento do aplicativo, por ser prática e eficiente para o uso educacional, além de disponibilizar funcionalidades para a geração de ferramentas multimídia para diversas plataformas de software,

*e-mail: nunes.ufc@gmail.com podendo ser executada em ambientes Microsoft Windows, Apple Mac OS e praticamente todas as distribuições de Linux ou mesmo sistemas operacionais de telefones celulares e tablets.

\section{O aplicativo}

A tela de abertura do software é dividida em duas partes. $\mathrm{Na}$ parte superior, três botões dão acesso a: (1) breve introdução ao tema polarimetria e os objetivos do aplicativo; (2) quiz composto por 15 questões de múltipla escolha; (3) créditos do desenvolvimento do aplicativo.

Na parte inferior, uma janela pop-up se abre para a escolha de 1 entre 11 compostos a serem estudados. Após a seleção do composto, um clique sobre o botão "avançar" leva o usuário a uma nova tela, onde é possível escolher um enantiômero puro ou uma mistura de enantiômeros para simular uma análise. A tela também disponibiliza o botão "saiba mais", que fornece informações e curiosidades sobre o composto selecionado.

Ao selecionar um dos enantiômeros, o usuário é conduzido a uma nova tela (Figura 1a). Na parte superior desta, uma animação mostra a polarização da luz e a eventual alteração do ângulo do plano da luz polarizada, desviando-o para a direita ou esquerda, durante a passagem através da solução contendo o composto quiral. Compostos aquirais estão associados a uma animação onde não ocorre desvio. Quando o composto for aquiral, não haverá alteração no ângulo do plano.

Na parte central da tela, existem duas barras de rolagem (slidebar) que alteram a concentração da solução (de 0 a $1 \mathrm{~g} / \mathrm{mL}$ ) e o comprimento da cela (de 1 a $3 \mathrm{dm}$ ). Ao deslocá-las, é possível verificar as relações existentes entre a concentração da solução e o comprimento da cela com a rotação óptica $(\alpha)$ e a rotação específica $\left([\alpha]_{D}\right)$ do composto. Na parte inferior da tela, é possível observar que a rotação específica $\left([\alpha]_{\mathrm{D}}\right)$ do composto sempre será constante, independentemente das escolhas da concentração e do tamanho da cela.

O botão "voltar" permite que o usuário retroceda e faça uma nova escolha. Ao selecionar a mistura de enantiômeros, é direcionado a outra tela (Figura 1b), também dividida em três partes. $\mathrm{Na}$ parte superior, encontra-se uma figura que representa o polarímetro 
e uma animação com estruturas 3D, em movimento de rotação, do par de enantiômeros. Na parte central desta tela, existem três barras de rolagem (slidebar) que alteram a concentração da solução, o comprimento da cela e a composição percentual da mistura. Nesta tela, o usuário novamente poderá observar que a rotação específica $\left([\alpha]_{\mathrm{D}}\right)$ do composto é independente da concentração da solução e do comprimento da cela. Todavia, ficará evidente que a rotação específica $\left([\alpha]_{\mathrm{D}}\right)$ observada será uma função da composição percentual da mistura, variando de $+[\alpha]_{D}$ a $-[\alpha]_{D}$, e vice-versa.

(a)

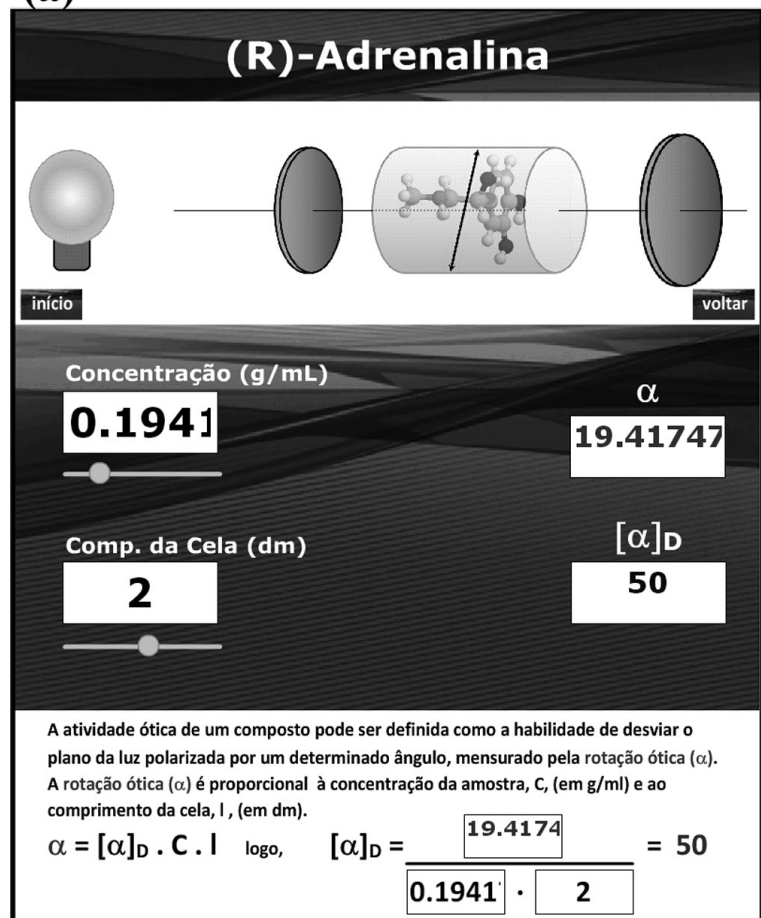

(b)

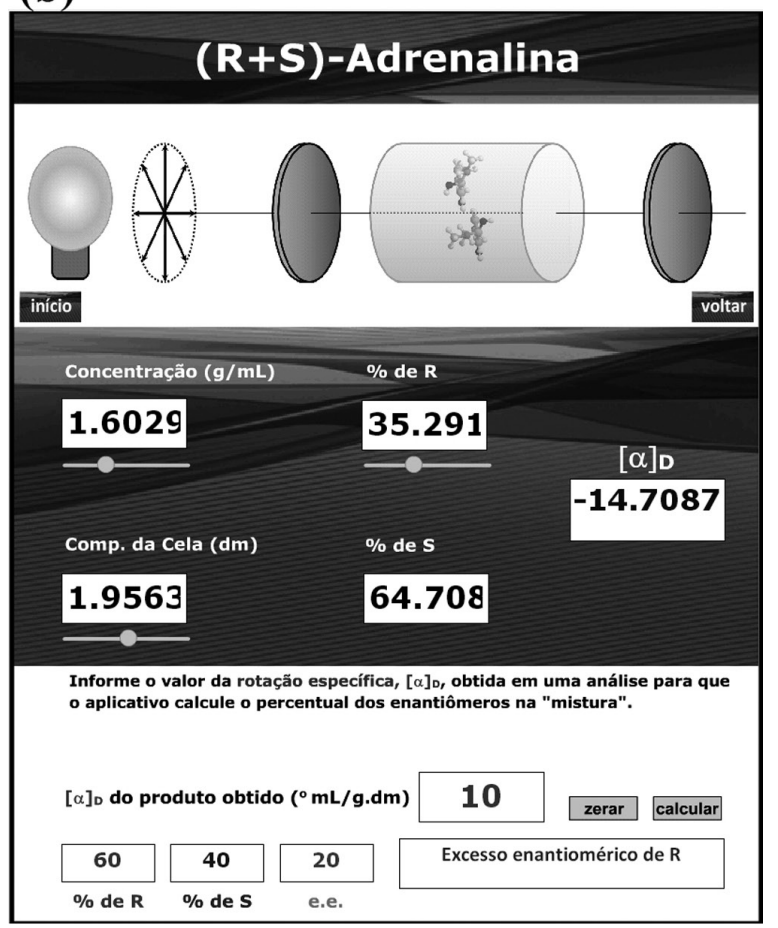

Figura 1. Tela de simulação de cálculos com enantiômero puro (a) e mistura de enantiômeros ( $b$ )
Na parte inferior, o usuário poderá inserir valores de rotação específica $\left([\alpha]_{\mathrm{D}}\right)$ e calcular a composição percentual dos enantiômeros $(\% R$ e $\% S)$ e o valor do excesso enantiomérico (e.e.) na mistura correspondente àquele valor de rotação específica inserido. Dependendo do valor de rotação específica inserido, o aplicativo também informa se a amostra em estudo é uma mistura racêmica, ou uma substância enantiomericamente pura, ou ainda de um excesso enantiomérico. Nestes dois últimos casos, os isômeros puros ou em excesso são especificados.

O botão "quiz" da tela inicial direciona o usuário a uma nova tela, onde poderá testar seus conhecimentos sobre polarimetria através de 15 questões de múltipla escolha, que se sucederão automaticamente ao se escolher uma das alternativas apresentadas. Ao responder a última questão, o aplicativo informará o percentual de acerto que o usuário obteve no quiz e o gabarito das questões.

\section{UTILIZAÇÃO}

A estratégia pedagógica para a utilização do software foi realizada no $2^{\circ}$ semestre de 2011, em turmas da disciplina Química Orgânica I, de 5 diferentes cursos de graduação da Universidade Federal do Ceará: Biologia (22), Biotecnologia (21), Farmácia (8), Odontologia (12) e Química (28).

Durante a aula, o professor projetava o aplicativo no quadro e, com o auxílio dos textos e animações presentes na seção "Introdução", apresentava as partes do polarímetro, os fenômenos de polarização e desvio da luz polarizada, bem como os conceitos relacionados à atividade óptica.

Em seguida, a seleção de compostos aquirais e quirais permitia a discussão da atividade óptica (habilidade de desvio da luz planopolarizada) das moléculas, através da variação da concentração da amostra e do comprimento da cela no polarímetro virtual, para verificar suas relações com os valores da rotação óptica $(\alpha)$ e rotação específica $\left([\alpha]_{D}\right)$ do composto selecionado. A seleção de uma mistura de enantiômeros permitia discutir a utilização da medida da rotação específica $\left([\alpha]_{\mathrm{D}}\right)$ como critério de pureza óptica da amostra em questão.

Na última etapa, os estudantes foram estimulados a manusearem o aplicativo durante seus estudos, com o intuito de se familiarizem com o software, fixarem os conceitos apresentados, levantarem dúvidas para serem discutidas na aula seguinte e avaliarem o aplicativo.

\section{AVALIAÇÃO}

Uma avaliação voluntária do software foi feita por 91 estudantes, utilizando-se um questionário impresso, composto de 10 afirmações. O estudante deveria manifestar a sua concordância com cada afirmação, assinalando um número em uma escala de 0-10 ("tipo Likert"), ${ }^{14}$ sendo que o número zero (0) significava "discordância plena" e o número dez (10) significava "concordância plena". Além da avaliação quantitativa, os estudantes avaliaram qualitativamente o aplicativo, através da indicação de pontos positivos e negativos, críticas, sugestões e comentários, e através da definição do mesmo com a utilização de uma única palavra.

\section{RESULTADOS E DISCUSSÃO}

Segundo os resultados do questionário de avaliação (Figura 2), pôde-se afirmar que o software foi bem aceito como uma ferramenta educacional. As concordâncias dos estudantes com as afirmações apresentadas variaram de 8,1 a 9,5. Portanto, podem-se considerar as afirmações como sendo verdadeiras, por estarem mais próximas da concordância plena (10) do que do ponto neutro (5) e muito mais distantes da não concordância (zero). Sendo assim, com boa 
exatidão pode-se afirmar que, do ponto de vista estético, as formas de representação da informação no software são visualmente agradáveis (afirmação 1, concordância 9,0) devido a uma interface gráfica simples e de fácil compreensão (afirmação 3, concordância 9,3), facilitando sua utilização (afirmação 2, concordância 9,5). A forma e o conteúdo do aplicativo despertam a curiosidade e o interesse dos estudantes (afirmação 4, concordância 8,8), motivados pelo elevado grau de interatividade do software (afirmação 5, concordância 8,7), estimulando o raciocínio dos estudantes (afirmação 9, concordância 9,1 ) e colocando-os numa situação de aprendizagem ativa (afirmação 7, concordância 9,0). Tais características nos levam a sugerir que o software pode contribuir para a melhoria do rendimento dos estudantes e para o aprendizado dos conceitos relacionados à polarimetria (afirmação 8, concordância 9,3), além de trazer vantagens sobre uma aula expositiva tradicional (afirmação 10 , concordância 8,1) e, desta forma, configura-se como uma ferramenta didático-computacional complementar que pode melhorar a qualidade do processo de ensino-aprendizagem (afirmação 6, concordância 8,3).

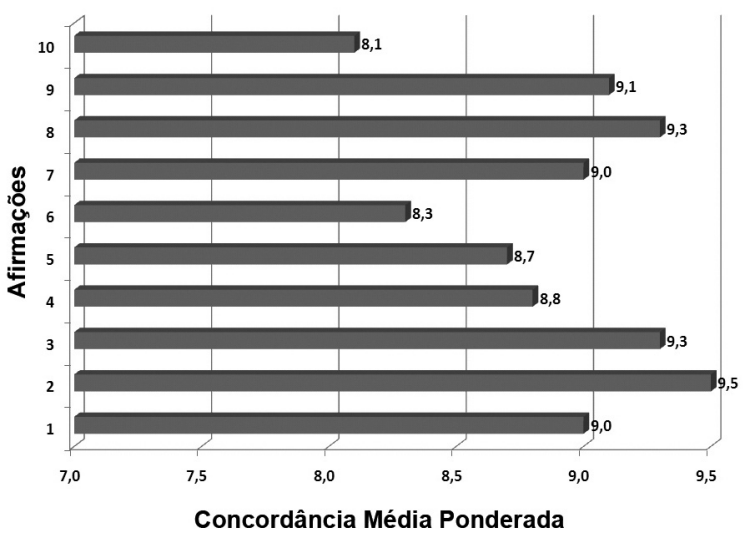

Figura 2. Distribuição dos valores médios ponderados das concordâncias dos estudantes em relação às afirmações: (1) do ponto de vista estético, as formas de representação da informação são visualmente agradáveis; (2)o software é de fácil utilização; (3) a interface gráfica é simples e de fácil compreensão; (4) a forma e o conteúdo do aplicativo despertam a curiosidade e o interesse do usuário; (5) o grau de interatividade do software é elevado; (6) o software pode melhorar o rendimento dos estudantes; (7) o software motiva o estudante e coloca-o numa situação de aprendizagem ativa; (8) o software contribui para o aprendizado dos conceitos relacionados à polarimetria; (9) o software estimula o raciocínio do estudante; (10) o software traz vantagem sobre uma aula tradicional (expositiva apenas)

Observando-se as cinco palavras mais citadas (Figura 3), conclui-se que os estudantes consideraram o aplicativo interessante $(16,5 \%)$, interativo (15,2\%), ótimo ou bom (11,8\%), didático (10,5\%) e prático $(15,3 \%)$. Desta forma, as avaliações, qualitativa e quantitativa, são

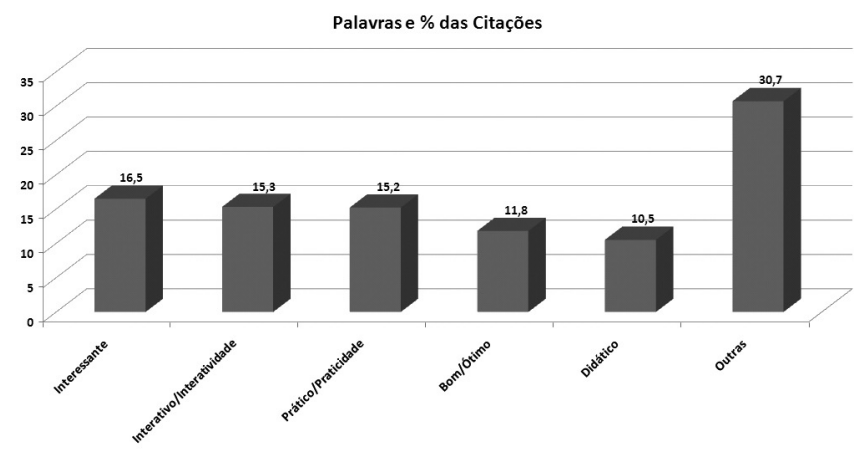

Figura 3. Distribuição percentual das palavras citadas coerentes, uma vez que todas as 85 citações validam positivamente o aplicativo.

Os simuladores no ensino de Química permitem a exploração de situações fictícias, de situações com risco, como manipulação de substâncias químicas ou objetos perigosos; de experimentos que são muito complicados, caros ou que levam muito tempo para se processarem. ${ }^{15}$ Desta forma, o software desenvolvido pode ser utilizado como uma ferramenta auxiliar de ensino-aprendizagem, que apresenta características de um simulador dinâmico e simplificado com algumas das funcionalidades de um polarímetro, permitindo aos usuários a possibilidade de desenvolver hipóteses, testá-las, analisar resultados e refinar os conceitos relacionados à atividade óptica.

O software está disponível gratuitamente no site do Curso de Química da Universidade Federal do Ceará: http://www.quimica. ufc.br/polarimetro.

\section{AGRADECIMENTOS}

Aos estudantes e aos Profs. D. Esdras, C. Oliveira, J. Mafezoli, M. Mattos e M. A. Lima, da UFC, que participaram da avaliação deste software.

\section{REFERÊNCIAS}

1. Ferreira, V. F.; Quim. Nova 1998, 21, 780.

2. Eichler, M.; Pino, J. C. D.; Quim. Nova 2000, 23, 835.

3. Benito, G. A. V.; Silva, B. A.; Jesus, H. P.; Santos, K. K.; Revista Texto e Contexto 2003, 12, 34 .

4. Michel, R.; Santos, F. M. T.; Greca, I. M. R.; Química Nova na Escola 2004, n ${ }^{\circ}$ 19, 3; http://www.labvirtq.fe.usp.br/indice.asp, acessada em Julho 2012; http://group.chem.iastate.edu/Greenbowe/sections/ projectfolder/simDownload/index4.html, acessada em Julho 2012.

5. Yokaichiya, D. K.; Fraceto, L. F.; Miranda, M. A.; Eduardo Galembeck, E.; Torres, B. B.; Quim. Nova 2004, 27, 489.

6. Dallacosta, A.; Fernandes, A. M. R.; Bastos, R. C.; Anais do $4^{o}$ Congresso da Rede Iberoamericana de Informática Educativa, Brasília, Brasil,1998.

7. Rocha, L. P.; Barbosa, A. A.; Freire, D. B. Q.; Santos, G. A.; Oliveira Jr., P. H.; Magalhães, V. B. B.; Anais do $7^{\circ}$ Simpósio Brasileiro de Educação Química, Salvador, Brasil, 2009.

8. Lima, J. B.; Silva, A. L. P.; Martins, N. C.; Costa, H. R.; Anais do $1^{o}$ Encontro Norte-Nordeste de Ensino de Química, São Luís, Brasil, 2009; Lona, L. M. F.; Roque, M. C.; Rodrigues, S.; Computers and Chemical Engineering 2000, 24, 1247.

9. Paiva, J. C.; Morais, C.; Boletim da Sociedade Portuguesa de Química 2006, $100,87$.

10. Ayres, A. C. S.; Sousa, M. P.; Santos, N.; Rapello, C. N.; Química Nova na Escola 2005, $\mathrm{n}^{\circ} 22,35$.

11. Silva Jr., J. N.; Leite Jr., A. J. M.; Pinto, Y. T. T.; Resumos do $10^{\circ}$ Encontro de Iniciação à Docência da Universidade de Fortaleza, Fortaleza, Brasil, 2010; Lima, J. B.; Bezerra, C. W. B.; Anais do $46^{\circ}$ Congresso Brasileiro de Química, Salvador, Brasil, 2006; Lima, J. B.; Silva, A. L. P; Costa, H. R.; Anais do $49^{\circ}$ Congresso Brasileiro de Química, Porto Alegre, Brasil, 2006.

12. Silva Jr., J. N.; Leite Jr., A. J. M., Sousa, J. R.; Resumos da $34^{a}$ Reunião Anual da Sociedade Brasileira de Química, Florianópolis, Brasil, 2011.

13. Adobe Flash, Adobe Systems Incorporated. Copyright (C) 2011.

14. Sax, G.; Principles of Educational and Psychological Measurement and Evaluation, $3^{\text {rd }}$ ed., Wadsworth Publishing Company: California, 1989; Hartley, J.; Betts, L. R.; Int. J. Social Research Methodology 2010, 13, 17; Dawes, J.; Int. J. Market Research 2008, 50, 61.

15. Valente, J. A.; Computadores e Conhecimento: Repensando a Educação, Gráfica da Unicamp: Campinas, 1993. 